\title{
Arabidopsis mutant dnd2 exhibits increased auxin and abscisic acid content and reduced stomatal conductance
}

Kale, Liga

2019-07

Kale , L , Nakurte , I , Jalakas , P , Kunga-Jegere , L , Brosche , M \& Rostoks , N 2019 , ' Arabidopsis mutant dnd2 exhibits increased auxin and abscisic acid content and reduced stomatal conductance ' , Plant Physiology and Biochemistry , vol. 140 , pp. 18-26 . https://doi.org/10.1016/j.plaphy.2

http://hdl.handle.net/10138/329707

https://doi.org/10.1016/j.plaphy.2019.05.004

cc_by_nc_nd

acceptedVersion

Downloaded from Helda, University of Helsinki institutional repository.

This is an electronic reprint of the original article.

This reprint may differ from the original in pagination and typographic detail.

Please cite the original version. 


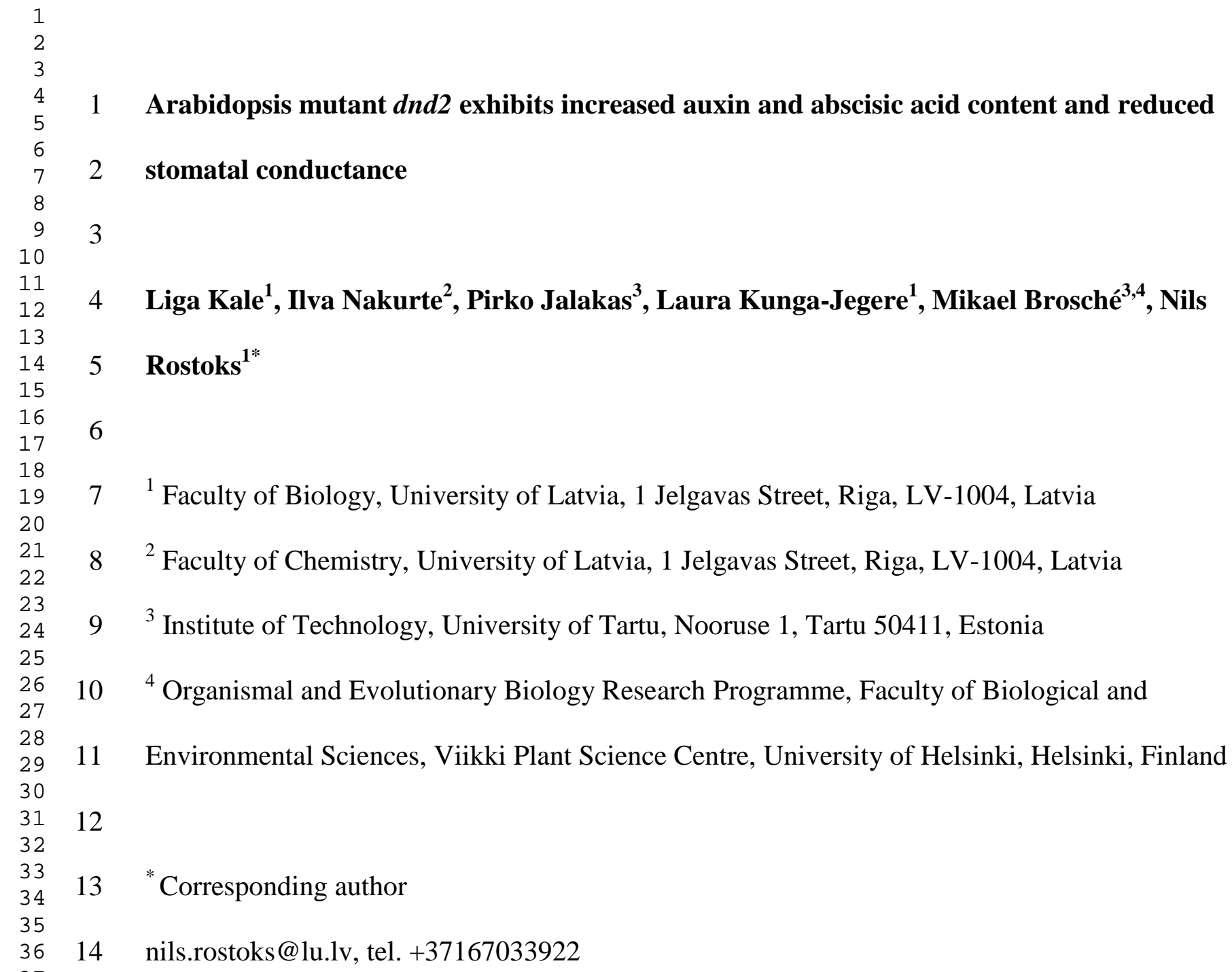

1 Arabidopsis mutant $d n d 2$ exhibits increased auxin and abscisic acid content and reduced

2 stomatal conductance

3

4 Liga Kale ${ }^{1}$, Ilva Nakurte ${ }^{2}$, Pirko Jalakas ${ }^{3}$, Laura Kunga-Jegere ${ }^{1}$, Mikael Brosché ${ }^{3,4}$, Nils

5 Rostoks $^{1 *}$

6

$7 \quad{ }^{1}$ Faculty of Biology, University of Latvia, 1 Jelgavas Street, Riga, LV-1004, Latvia

$8 \quad{ }^{2}$ Faculty of Chemistry, University of Latvia, 1 Jelgavas Street, Riga, LV-1004, Latvia

$9{ }^{3}$ Institute of Technology, University of Tartu, Nooruse 1, Tartu 50411, Estonia

$10{ }^{4}$ Organismal and Evolutionary Biology Research Programme, Faculty of Biological and

11 Environmental Sciences, Viikki Plant Science Centre, University of Helsinki, Helsinki, Finland 12

$13 *$ Corresponding author

14 nils.rostoks@lu.lv, tel. +37167033922 
15 Abstract

16 Arabidopsis thaliana cyclic nucleotide-gated ion channel gene 4 (AtCNGC4) loss-of-function

17 mutant $d n d 2$ exhibits elevated accumulation of salicylic acid (SA), dwarfed morphology,

18 reduced hypersensitive response (HR), altered disease resistance and spontaneous lesions on

19 plant leaves. An orthologous barley mutant, necl, has been reported to over-accumulate indole-

203 -acetic acid (IAA) and to exhibit changes in stomatal regulation in response to exogenous

21 auxin. Here we show that the Arabidopsis $d n d 2$ over-accumulates both IAA and abscisic acid

22 (ABA) and displays related phenotypic and physiological changes, such as, reduced stomatal

23 size, higher stomatal density and stomatal index. $d n d 2$ showed increased salt tolerance in root

24 growth assay and significantly reduced stomatal conductance, while maintaining near wt reaction

25 in stomatal conductance upon external application of ABA, and probably consequently increased

26 drought stress tolerance. Introduction of both sid2-1 and fmol into dnd2 background resulting in

27 removal of SA did not alter stomatal conductance. Hence, the closed stomata of $d n d 2$ is probably

28 a result of increased ABA levels and not increased SA levels. The triple $d n d 2$ sid2abil-1 mutant

29 exhibited intermediate stomatal conductance compared to $d n d 2$ and abil-1 (ABA insensitive,

30 open stomata), while the response to external ABA was as in abil-1 suggesting that reduced

31 stomatal conductance in $d n d 2$ is not due to impaired ABA signalling. In conclusion, Arabidopsis

32 dnd2 mutant exhibited ABA overaccumulation and stomatal phenotypes, which may contribute

33 to the observed improvement in drought stress resistance. Thus, Arabidopsis $d n d 2$ mutant may

34 serve as a model for studying crosstalk between biotic and abiotic stress and hormonal response

35 in plants.

36

37 Keywords: Arabidopsis $d n d 2$, barley nec 1 , auxin, abscisic acid, drought stress

38 


\section{Introduction}

Plant lesion mimic mutants (LMM) are essential tools for understanding mechanisms of

41 the hypersensitive response (HR) and plant disease resistance (Bruggeman et al., 2015; Lorrain 42 et al., 2003). The link between plant disease resistance and hormonal response and abiotic stress

43 tolerance is becoming increasingly established (Andersen et al., 2018; Kazan and Manners,

44 2009; Moeder et al., 2010). Arabidopsis $d n d 2$ and $h \operatorname{lm} 1$ mutants have mutations in the AtCNGC4

45 gene leading to the disruption of cyclic nucleotide-gated ion channel 4 gene, which causes

46 multiple phenotypes including elevated accumulation of salicylic acid (SA), defective seed

47 development, dwarfed plant size, delayed growth and time of flowering, defective reproduction,

48 changed leaf shape, reduced hypersensitive response, altered disease resistance, spontaneous

49 lesions on plant leaves and defective programmed cell death (PCD) during pathogen attack,

50 while maintaining effective gene-for-gene resistance and elevated thermal tolerance (Balague et

51 al., 2003; Finka et al., 2012; Genger et al., 2008; Jurkowski et al., 2004; Mercier et al., 2004).

52 While the phenotypes of the $d n d 2$ mutant have been well characterized, the molecular

53 mechanisms that lead to them are not entirely clear, and, in addition to the already identified SA

54 and reactive oxygen species (ROS) pathways and suspected $\mathrm{Ca}^{2+}$ signaling (Chin et al., 2013),

55 may include other unknown signals. Different members of CNGC gene family may have

56 different roles in $\mathrm{Ca}^{2+}$ signaling, e.g., $C N G C 5$ and $C N G C 6$ genes apparently encode cGMP-

57 activated nonselective $\mathrm{Ca}^{2+}$-permeable cation channels in the plasma membrane of Arabidopsis

58 guard cells (Wang et al., 2013), while the Arabidopsis CNGC2 was demonstrated to mediate

$59 \mathrm{Ca}^{2+}$ influx in mammalian HEK293T cells and in Arabidopsis leaf cells (Leng et al., 1999; Wang

60 et al., 2017). Recently, Arabidopsis $d n d l$ was reported to have reduced auxin sensitivity,

61 impaired auxin signaling and reduced increase in $\mathrm{Ca}^{2+}$ after treatment with exogenous auxin, 
62 suggesting that $\mathrm{CNGC2}$ may be involved in auxin-mediated $\mathrm{Ca}^{2+}$ signaling (Chakraborty et al.,

63 2018). Considering that Arabidopsis $\mathrm{CNGC} 2$ and $\mathrm{CNGC} 4$ are involved in the same signaling

64 pathways and have been shown to form homomeric and heteromeric ion channels in plants (Chin 65 et al., 2013), similar $\mathrm{Ca}^{2+}$ response in the $d n d 2$ mutant can be expected compared to $d n d 1$.

66 Previously, a possible auxin phenotype of $d n d 2$ mutant was hypothesized (Sherman and Fromm, 67 2009); however, no information is available on auxin content and responses in $d n d 2$. $d n d 2$ plants 68 have elevated plant disease resistance, but the mechanisms have not been discovered in detail.

69 Thus, it is possible that phytohormones other than SA participate in $d n d 2$ disease resistance.

70 Auxin and/or its signaling pathways may regulate plant disease resistance directly (Kazan and

71 Manners, 2009). Auxin could also play an indirect role by inducing changes in plant

72 development and altering plant and stomatal size and preventing plants from pathogen

73 penetration via stomata (Melotto et al., 2008; Melotto et al., 2006).

75 1998), as well as responses to variety of abiotic stresses including salt and drought stress (Cutler 76 et al., 2010; Finkelstein, 2013). CNGC genes have been shown to be induced under salinity stress 77 in chrysanthemum leaves and roots (Cheng et al., 2018). Recently, the wheat TaCNGCl4 gene, 78 which is an ortholog of the $A t C N G C 2$ gene, was found to be significantly upregulated during 79 ABA treatment (Guo et al., 2018); however, no relation between $d n d 2$ mutant and ABA has been 80 shown until now. Regulation of stomatal closure to optimize transpiration is a key step in 81 preventing plants from water loss. Transpiration is mediated by a turgor-driven change in volume 82 of the two surrounding guard cells (Yu et al., 2008). Many factors can influence the guard cell 83 turgor change including light, phytohormones, potassium and calcium ions, malate, NO, and $84 \mathrm{H}_{2} \mathrm{O}_{2}$ (Assmann, 2003; Nilson and Assmann, 2007; Schroeder et al., 2001; Shimazaki et al., 
85 2007). Additionally, overaccumulation of ABA has been demonstrated in Arabidopsis lesion

86 mimic mutant cpr22 that contains a fusion of $C N G C 11$ and $C N G C 12$ genes (Mosher et al.,

87 2010). ABA is also known as one of the regulators of drought stress tolerance in plants (Sauter et 88 al., 2001). The role of ABA in pathogen defense is poorly understood, although there are some 89 reports revealing correlation between ABA levels and resistance to pathogens (Mauch-Mani and 90 Mauch, 2005). ABA is also one of the players in the regulation of stomatal closure, which is part 91 of the innate immune system against bacterial infection. In view of this, it would be of interest to 92 determinate auxin and ABA content of $d n d 2$ plants and measure stomatal characteristics, which 93 could indirectly affect $d n d 2$ resistence to Pseudomonas syringae.

94 The orthologous mutant in barley, necl (Rostoks et al., 2006), has been shown to possess 95 essentially the same "defense-no-death" phenotype as $d n d 2 / h l m l$ (Keisa et al., 2011) and 96 provides significantly reduced disease development caused by fungal pathogens Ramularia 97 collo-cygni and Fusarium culmorum (McGrann et al., 2015). However, necl also exhibits 98 reduced stomatal conductance and aperture, altered response to exogenous auxin and increased 99 level of endogenous indole-3-acetic acid (Keisa et al., 2013). In this study we characterized IAA 100 and ABA content and expression of relevant genes in Arabidopsis $d n d 2$ mutant, as well as 101 changes in its physiological responses and its drought tolerance.

\section{Material and methods}

\subsection{Arabidopsis mutants}

Arabidopsis mutants used in the study are described in the Table 1. Arabidopsis accession

Col-0, as well as mutants $d n d 2-1$ and $a b a 2-1$ were obtained from the European Arabidopsis Stock Centre (http://arabidopsis.info/). Arabidopsis fmo1, sid2 and abil-1 mutants were gifts 
from Dr. Hans Thordal-Christensen, Dr. Jean-Pierre Métraux and Dr Julian Schroeder, respectively. Double and triple mutants were generated through crossings. Mutations were confirmed in $\mathrm{F}_{2}$ and $\mathrm{F}_{3}$ generations by using cleaved amplified polymorphic sequences (CAPS)

111 primer-based PCR for dnd2-1, sid2-1, abi1-1, and aba2-1, and PCR genotyping for fmol. Primer

112 sequences for genotyping are provided in Table 2.

\section{2.2. Measurements of IAA and ABA}

114 Non-conjugated forms of IAA and ABA were extracted and determined by HPLC-UV-FLD as

115 described previously (Nakurte et al., 2012). Briefly, the plant material was ground in liquid

116 nitrogen and the samples were weighted and extracted with $100 \%$ methanol $\left(2.5 \mathrm{~mL} \mathrm{~g}^{-1}\right.$ of fresh

117 weight $(\mathrm{FW}))$. The extract was cleared by centrifugation at 4,000 $\mathrm{g}$ for $10 \mathrm{~min}$ at room

118 temperature. The resulting supernatant was transferred to a new tube and evaporated until the

119 volume decreased to less than one-tenth of the initial. The evaporated residue was dissolved in a

$1201 \%$ acetic acid solution $\left(2.5 \mathrm{~mL} \mathrm{~g}^{-1} \mathrm{FW}\right)$ and filtered with $0.20 \mu \mathrm{m}$ filters (Nonpyrogenic Sterile-

$121 \mathrm{R}$, Sarstedt) to remove particulate and other suspended solid matter. The filtered samples were

122 immediately preconcentrated by SPE using AccuBOND II ODSC18 $200 \mathrm{mg} 3 \mathrm{~mL}$ SPE (Agilent

123 Technologies, Santa Clara, CA, USA). C18 SPE columns were pretreated with $2.5 \mathrm{~mL}$ of

124 methanol followed by $2.5 \mathrm{~mL}$ of $1 \mathrm{M}$ acetic acid. Samples (approximately $2.5 \mathrm{~mL}$ ) were loaded

125 on the cartridge, the column was washed with $2.5 \mathrm{~mL}$ of $1 \mathrm{M}$ acetic acid and methanol $(2.5 \mathrm{~mL})$

126 was used to elute the analytes from the extraction column. The extract was evaporated till

127 dryness and redissolved in $300 \mu \mathrm{L}$ of the mobile phase $(60 \%$ methanol and $40 \%$ of $1 \%$ acetic

128 acid v/v)). Standards of indole- 3-acetic acid (>99\%), and ABA (99\%) were purchased from

129 Sigma-Aldrich (St. Louis, MO, USA). 
131 consisting of quaternary pump, autosampler, column thermostat, UV and fluorescence detectors

132 (Agilent Technologies, Santa Clara, CA, USA). HPLC separations were achieved by using a 133 reverse-phase Zorbax Eclipse XDB-C8 (Agilent Technologies, Santa Clara, CA, USA) column $1344.6 \times 150 \mathrm{~mm}, 5 \mu \mathrm{m}$. Colum temperature was controlled at $30^{\circ} \mathrm{C}$. Mobile phase was composed of 135 methanol and $1 \%$ acetic acid $(60: 40, \mathrm{v} / \mathrm{v})$ in isocratic mode at a flow rate of $1 \mathrm{~mL} \mathrm{~min}^{-1}$. The 136 detection of ABA was monitored using UV detection at $270 \mathrm{~nm}$ and the detection of IAA was 137 monitored using FLD detection at $282 \mathrm{~nm}$ (Ex) $360 \mathrm{~nm}$ (Em). Injection volume was $50 \mu \mathrm{L}$. 138 Results were evaluated by a ChemStation Plus (Agilent, Santa Clara, CA, USA).

Plants for the experiment were germinated in pots (Arasystem, Betatech bvba, Ghent, Belgium) filled with a mixture of half soil and half vermiculite. After seven days seedlings were transplanted in new pots and grown for one month. For ABA content measurements during drought stress leaf samples were collected two days after withholding water (drought stress) or from routinely watered control plants. Plants were grown in a growth chamber under long-day (16 h day, $8 \mathrm{~h} \mathrm{night),} 22^{\circ} \mathrm{C}$ and medium light (ca. $150 \mu \mathrm{mol} \mathrm{m}^{-2} \mathrm{~s}^{-1}$ ) growing conditions.

Histochemical visualization of endogenous IAA level in Col-0 and $d n d 2$ plants was done using pIAA2-GFP-GUS reporter gene system crossed into $d n d 2$ background according to a published

\subsection{Effects of IAA, $A B A$ and $\mathrm{NaCl}$ on root elongation}

Seeds were surface sterilized in $2.5 \%$ bleach solution and incubated at $4^{\circ} \mathrm{C}$ for three days to synchronize the germination. Seedlings were grown on Murashige and Skoog (MS basal medium) supplemented with $0.8 \%$ agar (Murashige and Skoog, 1962). Plants were grown on 
153 Petri plates in a growth chamber under long-day ( $16 \mathrm{~h}$ day, $8 \mathrm{~h}$ night $), 22^{\circ} \mathrm{C}$ and medium light 154 (ca. $150 \mu \mathrm{mol} \mathrm{m} \mathrm{m}^{-2} \mathrm{~s}^{-1}$ ). After growth in MS medium for seven days, plants were transferred to 155 Petri plates with fresh medium containing different concentrations of IAA and ABA or $100 \mathrm{mM}$ $156 \mathrm{NaCl}$. During the transfer dots were marked on Petri plates showing the tip of primary root. Petri 157 plates were incubated vertically, and the increase in length of primary roots from dots 158 (elongation) was measured after seven days from digital images using Image $\mathrm{J}$ software 159 (Schneider et al., 2012). Results are average measurements of at least 10 seedlings per treatment 160 from three independent experiments. Results were expressed as a percentage from untreated 161 plant root elongation.

\subsection{RNA extraction and quantitative real-time PCR}

Total RNA extraction from Col-0 and $d n d 2$ rosette leaves, cDNA synthesis, and 170 involved in degradation of Aux/IAA proteins (Tan et al. 2007), while CSN5 has been shown to 171 modulate auxin response in COP9 signalosome (CSN) complex with SCFTIR1 (Dohmann et al., 172 2008). YUCCA flavin monooxygenases encoded by different $Y U C$ genes are implicated in auxin 173 biosynthesis via indole-3-pyruvic acid (IPyA) pathway (Di et al., 2016), while TRYPTOPHAN 174 AMINOTRANSFERASE OF ARABIDOPSIS1 (TAA1) has been shown to convert L175 tryptophan to IPyA and AMI1 is involved in conversion of indole-3-acetamide (IAM) to IAA 

(Mano and Nemoto, 2012). ABA INSENSITIVE1 encoding protein phosphatase 2C is a known negative regulator of ABA signaling (Gosti et al., 1999) and is itself upregulated by external ABA applications (Hoth et al., 2002). ABI4 gene encodes an AP2 domain transcription factor (Söderman et al., 2000) which functions as a positive regulator of ABA signaling.

Primers used for qPCR analysis are listed in Table 2. Relative gene expression in $d n d 2$ 181 was calculated using $2^{-\Delta \Delta C t}$ method (Livak and Schmittgen, 2001) and gene expression was 182 normalized to the AtACTIN2 gene, which is commonly used for normalization of gene 183 expression data in Arabidopsis and its expression is not affected by external application of ABA 184 (Hoth et al., 2002). Gene expression in $d n d 2$ was shown relative to the expression in Col-0 185 plants. Plants for the experiment were grown as described above for quantification of IAA and $186 \mathrm{ABA}($ section 2.2).

\subsection{Drought stress treatment}

Plants for the drought stress treatment were germinated in pots (Arasystem, Betatech bvba, Ghent, Belgium) filled with a mixture of half soil and half vermiculite and watered three times a week, ensuring soil saturation. After seven days seedlings were individually transplanted in new pots and irrigated with $5 \mathrm{ml}$ water on day one, four and seven after transplantation. On day 14 after germination drought stress was induced by withholding water for 12 days and removing baskets from plastic tray for increased water evaporation. Plants were grown in a growth chamber under long-day ( $16 \mathrm{~h}$ day, $8 \mathrm{~h}$ night), $22^{\circ} \mathrm{C}$ and medium light (ca. $150 \mu \mathrm{mol} \mathrm{m} \mathrm{m}^{-2} \mathrm{~s}^{-1}$ ) conditions with constant ventilation. Majority of Col-0 plants showed clear symptoms of wilting that were considered as severe drought stress. The survival rates were evaluated after five days of 

total $56 d n d 2$ and 56 Col-0 plants per treatment.

\subsection{Measurements of stomatal density, index and sizes}

Plants for the experiment were grown as described in section 2.5. in Arasystem pots

(Betatech bvba, Ghent, Belgium) filled with a mixture of soil and vermiculite (1:1) under normal watering regime. Leaves from one-month old $d n d 2$ and Col-0 plants were used for stomatal measurements. Stomatal sizes were determined by light microscopy. Nail polish images from silicone rubber imprints of abaxial surfaces of rosette leaves were photographed and measured according to Casson et al., 2009. Stomatal density and stomatal index were calculated as described by Royer, 2001.

\subsection{Measurement of stomatal conductance}

Arabidopsis seeds were planted in soil containing 2:1 (v:v) peat : vermiculite and grown 212 as described by (Kollist et al., 2007). Briefly, the plants were grown in growth chambers (AR213 66LX, Percival Scientific, IA, USA and Snijders Scientific, Drogenbos, Belgium) with 12 h 214 photoperiod, $23{ }^{\circ} \mathrm{C}$ day, $18^{\circ} \mathrm{C}$ night temperature, $150 \mu \mathrm{mol} \mathrm{m} \mathrm{s}^{-2}$ light and $70 \%$ relative 215 humidity. Plants were 24-32 days old during gas exchange experiments.

216 Whole-plant stomatal conductance response to exogenous ABA was measured as 217 described by Merilo et al. (2015) with a custom made rapid-response gas exchange measurement 218 device (Kollist et al., 2007). Intact plants were sprayed with $5 \mu \mathrm{M}$ ABA solution (distilled water, $219 \quad 0.012 \%$ Silwet L-77 (Duchefa), $0.05 \%$ ethanol). After spraying stomatal conductance was measured for $40 \mathrm{~min}$. Due to the small size of rosette leaves stomatal conductance of $d n d 2 a b a 2-1$ 
plants was not measured (Supplemental figure 1). ANOVA with Tukey unequal N HSD post hoc test was used to identify significant differences among Col-0 and all the mutants at $P<0.05$.

\section{Results and discussion}

Plant LMMs that exhibit spontaneous cell death, changes in the hypersensitive response and disease resistance in the absence of pathogen have proved useful to unravel the mechanisms of plant disease resistance (Lorrain et al., 2003; Moeder et al., 2011). Recently, the interplay between plant hormonal signaling and disease resistance involving salicylic acid, auxin and abscisic acid (ABA) has been established in some detail (Kazan and Manners, 2009; Moeder et al., 2010). The barley mutant necl, which is an orthologue of Arabidopsis $d n d 2$ (Rostoks et al., 2006), was found to exhibit similar disease resistance response as $d n d 2$ (Keisa et al., 2011), while also containing increased level of indole-3-acetic acid (IAA) and showing altered auxin response and reduced stomatal conductance (Keisa et al., 2013). In this study, the levels of free IAA and ABA in Arabidopsis $d n d 2$ were studied using HPLC-UV-FLD. Approximately 2.5-fold increase of IAA in shoots and 1.4-fold increase in roots was found in $d n d 2$ compared to Col-0 (Fig. 1A). The 2.5-fold increase of IAA content in $d n d 2$ shoots was somewhat smaller than that 237 found in barley nec1, which showed 4-fold increase of IAA in both shoots and roots. In terms of 238 absolute quantity, IAA content in the Arabidopsis Col-0 shoots and roots was 49 and $30 \mathrm{ng} \mathrm{g}^{-1}$ 239 fresh weight (FW), respectively, which was comparably higher than in wt barley shoots and roots $240-14$ and $2.4 \mathrm{ng} \mathrm{g}^{-1} \mathrm{FW}$. dnd 2 shoots and roots contained 123 and $44 \mathrm{ng} \mathrm{g}^{-1} \mathrm{FW}$ IAA, 241 respectively, while barley necl shoots and roots contained 60 and $10 \mathrm{ng} \mathrm{g}^{-1} \mathrm{FW}$ IAA, 242 respectively (Keisa et al., 2013). Thus, orthologous $d n d 2$ and nec1 mutants both showed 
significant increase in auxin content compared to their respective wt plants, although the IAA content in wt plants from both species was different.

Under normal growth conditions $d n d 2$ leaves accumulated about 80 -fold more ABA than Col-0 plants (98.6 vs. $1.2 \mathrm{ng} \mathrm{g}^{-1} \mathrm{FW}$ ) (Fig. 1B). Under drought stress conditions Col-0 plants exhibited approximately 27 -fold $\mathrm{ABA}$ induction in leaves $\left(34 \mathrm{ng} \mathrm{g}^{-1} \mathrm{FW}\right)$, while $d n d 2$ plants showed smaller 1.4-fold induction of ABA in leaves (134 $\left.\mathrm{ng} \mathrm{g}^{-1} \mathrm{FW}\right)$. Nevertheless, level of $\mathrm{ABA}$ in $d n d 2$ plants under drought stress was 4-fold higher than in Col-0 (Fig. 1B). The ABA content in barley was below limit of detection in both wt and barley necl mutant (Nakurte et al., 2012); therefore no comparison with $d n d 2$ was possible.

The Arabidopsis line carrying the pIAA2-GUS reporter gene was crossed with $d n d 2$ mutant and the resulting $\mathrm{F}_{2}$ homozygous progeny was used to assay the auxin distribution in $d n d 2$ plants in comparison with Col-0. The pattern of auxin-inducible GUS expression indicated that the location of auxin and auxin signaling in $d n d 2$ was similar to Col- 0 , while the somewhat stronger reporter gene signal was consistent with the observed IAA increase in $d n d 2$ (Fig. 2).

To study potential causes for the observed increase in IAA and ABA content, the expression of several IAA and ABA response-linked genes were studied in $d n d 2$ leaves (Fig. 3). Significantly increased expression was observed for AMII and CSN5 genes, which are involved in conversion of indole-3-acetamide (IAM) to IAA (Mano and Nemoto, 2012) and in regulation of auxin responses via interaction of COP9 signalosome (CSN) complex with $\mathrm{SCF}^{\mathrm{TIR} 1}$ (Dohmann et al., 2008), respectively. Thus, increased auxin content in $d n d 2$ may be caused by increased IAA biosynthesis through IAM pathway, while differences in auxin response may relate to activity of CSN complex or slightly decreased expression of auxin receptor TIRI. Of the three YUCCA flavin monooxygenase genes which have been implicated in auxin biosynthesis 
via indole-3-pyruvic acid (IPyA) pathway (Di et al., 2016), only the YUC2 gene showed slightly decreased expression. Increased expression of $A B I I$ and $A B I 4$ genes, encoding protein phosphatase $2 \mathrm{C}$ and $\mathrm{AP} 2$ domain transcription factor, respectively, that are involved in $\mathrm{ABA}$ signal transduction may explain the observed changes in response to exogenous ABA application. ABII expression was shown to be increased by exogenous ABA treatment in Arabidopsis by massively parallel signature sequencing (Hoth et al., 2002), while it has been shown that ABI1 is a negative regulator of ABA signaling (Gosti et al., 1999). Thus, increased expression of $A B I 1$ in $d n d 2$ plants may be a compensatory mechanism to reduce ABA signaling caused by higher levels of endogenous ABA. Increase of $A B I 1$ expression has also been observed in another lesion mimic mutant, $c p r 22$ with defective cyclic nucleotide-gated ion channel genes, although, unlike $d n d 2$, reduced responsiveness to ABA was observed in $c p r 22$ (Mosher et al., 2010).

The physiological effects of altered IAA and ABA content were studied in $d n d 2$ using root elongation assay and under the drought stress. ABA is a mediator for several plant adaptive responses to abiotic stresses including drought and salinity stress (Fernando and Schroeder, 2016). Arabidopsis usually shows inhibited root growth, when treated with $\mathrm{NaCl}$ (Xu et al., 2008). Salt stress involves rapid and massive accumulation of ABA, which acts on endodermis 283 and prevents root growth (Duan et al., 2013; Jia et al., 2002). The effects of exogenously applied 284 IAA, ABA and $\mathrm{NaCl}$ were studied by measuring by how much the root growth (elongation) was 285 reduced in treated plants (Fig. 4A-C). Increasing concentrations of exogenous IAA reduced the 286 root growth in the $d n d 2$ significantly more than in Col-0 (Fig. 4A), which may be linked to 287 already elevated level of IAA in $d n d 2$. At the same time $d n d 2$ root growth appeared to be more 288 insensitive to $\mathrm{ABA}$ and $\mathrm{NaCl}$ treatment than $\mathrm{Col}-0$ (Fig. 4B, C). While the simplest explanation 
is that increase in endogenous IAA concentration in combination with exogenous application contributes to reduced root growth in $d n d 2$ mutant, the crosstalk between IAA and ABA in root growth regulation may be involved (Wang et al., 2011; Xu et al., 2013). Even though different concentrations are usually used for root growth (elongation) assays for barley and Arabidopsis, the same trend in root growth was observed in both barley and Arabidopsis by applying increasing IAA concentration (Keisa, 2013). However, under relatively high IAA concentration Arabidopsis $d n d 2$ maintained sensitivity and showed increasing root shortening, while the barley necl lost sensitivity and exhibited longer roots than wt plants (Keisa, 2013). This observation may be due to the fact that increase of IAA in Arabidopsis $d n d 2$ was smaller than in barley nec1 compared to respective wt plants. In order to reach auxin homeostasis, IAA levels may need to be reduced in necl; however, the process of reducing IAA levels in plants is not clearly defined. Some of the known IAA catabolism pathways involve IAA oxidation to 2-oxindole-3-acetic acid (oxIAA) and conjugation to amino acids or sugars (Normanly, 2010). Further studies on IAA conjugate content in barley necl and Arabidopsis $d n d 2$ would be necessary to cover this issue, as increased IAA level may be due to increased biosynthesis or altered catabolism which may also be affected by abiotic stress conditions (Feng et al., 2015).

A common defense response to several abiotic stresses including drought, cold and salt stress is activation of ABA signaling (Fernando and Schroeder, 2016). Considering the elevated amount of $\mathrm{ABA}$ in $d n d 2$ and differences in response to external $\mathrm{ABA}$ and $100 \mathrm{mM} \mathrm{NaCl}$ 308 between $d n d 2$ and Col-0 in root elongation assay (Fig. 4B, C), it was relevant to study the $d n d 2$ 309 response to drought stress. The drought stress test showed that $d n d 2$ mutant plants survived the 310 drought period much better than Col-0 plants (Fig. 5). Severe drought stress using water 311 withdrawal for 12 days resulted in wilting and drying of most of the Col-0 plants (Fig. 5A), but 
312 did not significantly affect $d n d 2$ plants (Fig. 5B). Once the watering was resumed, over $80 \%$ of dnd2 plants survived, while most of the Col-0 plants did not recover (recovery rate 6.5\%; Fig. 5C). The increased ABA content and reduced stomatal size (Fig. 6A) may explain the increased drought resistance of $d n d 2$ plants, although $d n d 2$ and Col-0 plants differ in development, which can also influence the response to drought stress. In addition, mutations in $C N G C 2$ and $C N G C 4$ genes have been shown to increase thermotolerance in Arabidopsis through accumutation of heat shock proteins (HSP) (Finka et al., 2012), which are often involved in responses to other abiotic stresses (dos Reis et al., 2012).

Since the level of ABA was increased in $d n d 2$ and the study on barley necl showed reduced stomatal conductance and aperture (Keisa et al., 2013), the stomatal characteristics of $d n d 2$ were studied. Measurements of stomatal length and width indicated that $d n d 2$ has smaller stomata than Col-0 (Fig. 6A) similarly to barley necl that showed reduced stomatal aperture (Keisa, 2013; Keisa et al., 2013). In addition, $d n d 2$ exhibited increased stomatal density per unit leaf area and increased stomatal index (Fig. 6B, C), which may represent a plant strategy to compensate for reduced stomatal size as supported by Franks and Beerling (2009). Similarly to barley necl, Arabidopsis $d n d 2$ exhibited constitutively lower stomatal conductance (Fig. 7A), while the application of exogenous ABA resulted in even further reduction of conductance (Fig. 7B). Since the stomatal conductance was already very low in $d n d 2$, the relative values were used to visualize the decrease in stomatal conductance upon $\mathrm{ABA}$ treatment. The $\mathrm{ABA}$ treatment resulted in even further decrease in stomatal conductance in $d n d 2$, indicating that ABA response was not impaired in $d n d 2$, although the decrease in stomatal conductance was somewhat slower than in Col-0 (Fig. 7B). To determine whether $d n d 2$ have more closed stomata due to increased ABA levels (Fig. 1B) or due to increased SA levels (Jurkowski et al., 2004), a genetics approach 
was used to remove SA from $d n d 2$. The sid2-1 mutant is defective in the main SA biosynthesis enzyme ISOCHORISMATE SYNTHASE1 (Nawrath and Métraux, 1999) and fmol encoding FLAVIN MONOOXYGENASE1 is defective in systemic acquired resistance (SAR) and exhibits lower level of SA (Hartmann et al., 2018; Mishina and Zeier, 2006). Removal of SA acid resulted in significantly increased rosette sizes in $d n d 2$ sid2fmol plants compared to $d n d 2$ plants, although they were still smaller than sid2fmol plants implying deficiency in other functions (Fig. 8, Supplemental figure 1). Introduction of both sid2-1 and fmo1 into dnd2 did not alter the stomatal conductance (Fig. 7). Hence, the closed stomata of $d n d 2$ was likely a result of increased ABA levels and not increased SA levels. To study the interaction between ABA and $d n d 2$, independent from SA, a combination mutant was constructed: $d n d 2$ sid2-1 (to remove SA) and abil-1 (a strong ABA insensitive mutant). As strong ABA insensitive mutants have very high stomatal conductance (Merilo et al., 2013), this combination of mutations would allow to determine, if the low stomatal conductance of $d n d 2$ could suppress the high stomatal conductance of abil-1. Furthermore, to exclude a role for SA, the sid2 mutation was included. The triple $d n d 2$ sid2-1abi1-1 mutant exhibited intermediate stomatal conductance compared to the $d n d 2$ and the ABA insensitive abil-1, while its response to external ABA was similar to abil-1 (Fig. 7). Overall the phenotype of $d n d 2$ is likely the result of several interacting signaling 352 pathways including responses to auxin, ABA and SA.

\section{Conclusions}

355 In conclusion, Arabidopsis $d n d 2$ mutant exhibited significantly increased IAA content in 356 leaves and roots and ABA content in leaves. In addition to constitutively increased ABA content, $357 d n d 2$ showed increased tolerance to salinity, near wt-like reaction to exogenous application of 
ABA, reduced stomatal conductance and probably consequently increased drought stress

tolerance. Thus, Arabidopsis $d n d 2$ mutant may provide a useful model for studying crosstalk

between biotic and abiotic stress and IAA and ABA response in plants. Further work on $d n d 2$ is

required to substantiate the link between abiotic stress response, disease resistance and hormone signaling.

\section{References}

Alcázar, R., García, A. V., Parker, J. E., Reymond, M., 2009. Incremental steps toward incompatibility revealed by Arabidopsis epistatic interactions modulating salicylic acid pathway activation. Proc. Natl. Acad. Sci. U. S. A. 106, 334-339.

Andersen, E. J., Ali, S., Byamukama, E., Yen, Y., Nepal, M. P., 2018. Disease resistance mechanisms in plants. Genes 9, 339.

Anderson, J. P., Badruzsaufari, E., Schenk, P. M., Manners, J. M., Desmond, O. J., Ehlert, C., Maclean, D. J., Ebert, P. R., Kazan, K., 2004. Antagonistic interaction between abscisic acid 
Assmann, S. M., Snyder, J. A., Lee, Y.-R. J., 2000. ABA-deficient (abal) and ABA-insensitive (abil-1, abi2-1) mutants of Arabidopsis have a wild-type stomatal response to humidity. Plant, Cell \& Environment 23, 387-395.

Assmann, S. M., 2003. OPEN STOMATA1 opens the door to ABA signaling in Arabidopsis guard cells. Trends Plant Sci. 8, 151-153.

Balague, C., Lin, B., Alcon, C., Flottes, G., Malmstrom, S., Kohler, C., Neuhaus, G., Pelletier, G., Gaymard, F., Roby, D., 2003. HLM1, an essential signaling component in the hypersensitive response, is a member of the cyclic nucleotide-gated channel ion channel family. Plant Cell 15, 365-379.

Bishopp, A., Help, H., El-Showk, S., Weijers, D., Scheres, B., Friml, J., Benková, E., Mähönen, Ari P., Helariutta, Y., 2011. A mutually inhibitory interaction between auxin and cytokinin specifies vascular pattern in roots. Curr. Biol. 21, 917-926.

Bruggeman, Q., Raynaud, C., Benhamed, M., Delarue, M., 2015. To die or not to die? Lessons from lesion mimic mutants. Front. Plant Sci. 6, 24.

Casson, S. A., Franklin, K. A., Gray, J. E., Grierson, C. S., Whitelam, G. C., Hetherington, A. M., 2009. phytochrome B and PIF4 regulate stomatal development in response to light quantity. Curr. Biol. 19, 229-234.

Chakraborty, S., Toyota, M., Moeder, W., Chin, K., Fortuna, A., Champigny, M., Vanneste, S., Gilroy, S., Beeckman, T., Yoshioka, K., 2018. A novel role for Cyclic Nucleotide-Gated Ion Channel 2 (DND1) in auxin signaling. bioRxiv, 508572. 
Cheng, P., Gao, J., Feng, Y., Zhang, Z., Liu, Y., Fang, W., Chen, S., Chen, F., Jiang, J., 2018. The chrysanthemum leaf and root transcript profiling in response to salinity stress. Gene 674, 161-169.

Chin, K., DeFalco, T. A., Moeder, W., Yoshioka, K., 2013. The Arabidopsis cyclic nucleotidegated ion channels AtCNGC2 and AtCNGC4 work in the same signaling pathway to regulate pathogen defense and floral transition. Plant Physiol. 163, 611-624.

Cui, F., Brosche, M., Shapiguzov, A., He, X.-Q., Vainonen, J., Leppälä, J., Trotta, A., Kangasjärvi, S., Salojärvi, J., Kangasjärvi, J., Overmyer, K., 2018. Methyl viologen can affect mitochondrial function in Arabidopsis. bioRxiv, 436543.

Cutler, S. R., Rodriguez, P. L., Finkelstein, R. R., Abrams, S. R., 2010. Abscisic acid: emergence of a core signaling network. Annu. Rev. Plant Biol. 61, 651-679.

Dharmasiri, N., Dharmasiri, S., Estelle, M., 2005. The F-box protein TIR1 is an auxin receptor. Nature 435, 441-445.

Di, D.-W., Zhang, C., Luo, P., An, C.-W., Guo, G.-Q., 2016. The biosynthesis of auxin: how many paths truly lead to IAA? Plant Growth Regulation 78, 275-285.

Dohmann, E. M., Levesque, M. P., Isono, E., Schmid, M., Schwechheimer, C., 2008. Auxin responses in mutants of the Arabidopsis CONSTITUTIVE PHOTOMORPHOGENIC9 signalosome. Plant Physiol .147, 1369-1379.

dos Reis, S. P., Lima, A. M., de Souza, C. R. B., 2012. Recent molecular advances on downstream plant responses to abiotic stress. Int. J. Mol. Sci. 13, 8628-8647.

Duan, L., Dietrich, D., Ng, C. H., Chan, P. M., Bhalerao, R., Bennett, M. J., Dinneny, J. R., 2013. Endodermal ABA signaling promotes lateral root quiescence during salt stress in Arabidopsis seedlings. Plant Cell 25, 324-341. 
Feng, S., Yue, R., Tao, S., Yang, Y., Zhang, L., Xu, M., Wang, H., Shen, C., 2015. Genomewide identification, expression analysis of auxin-responsive GH3 family genes in maize (Zea mays L.) under abiotic stresses. J. Integr. Plant Biol. 57, 783-795.

Fernando, V. C. D., Schroeder, D. F., 2016. Role of ABA in Arabidopsis salt, drought, and desiccation tolerance, in: Shanker, A.K., Shanker, C. (Eds.), Abiotic and biotic stress in plants - recent advances and future perspectives. IntechOpen, Rijeka, pp. 507-524.

Finka, A., Cuendet, A. F., Maathuis, F. J., Saidi, Y., Goloubinoff, P., 2012. Plasma membrane cyclic nucleotide gated calcium channels control land plant thermal sensing and acquired thermotolerance. Plant Cell 24, 3333-3348.

Finkelstein, R., 2013. The Arabidopsis Book. American Society of Plant Biologists, pp. 1-36.

Franks, P. J., Beerling, D. J., 2009. Maximum leaf conductance driven by CO2 effects on stomatal size and density over geologic time. Proc. Natl. Acad. Sci. U S A 106, 1034310347.

Genger, R. K., Jurkowski, G. I., McDowell, J. M., Lu, H., Jung, H. W., Greenberg, J. T., Bent, A. F., 2008. Signaling pathways that regulate the enhanced disease resistance of Arabidopsis "defense, no death" mutants. Mol. Plant Microbe Interact. 21, 1285-1296.

Gosti, F., Beaudoin, N., Serizet, C., Webb, A. A., Vartanian, N., Giraudat, J., 1999. ABI1 protein phosphatase $2 \mathrm{C}$ is a negative regulator of abscisic acid signaling. Plant Cell 11, 1897-1910.

Guo, J., Islam, M. A., Lin, H., Ji, C., Duan, Y., Liu, P., Zeng, Q., Day, B., Kang, Z., Guo, J., 2018. Genome-wide identification of Cyclic Nucleotide-Gated Ion Channel gene family in wheat and functional analyses of TaCNGC14 and TaCNGC16. Front. Plant Sci. 9, 18.

Hartmann, M., Zeier, T., Bernsdorff, F., Reichel-Deland, V., Kim, D., Hohmann, M., Scholten, N., Schuck, S., Bräutigam, A., Hölzel, T., Ganter, C., Zeier, J. 2018. Flavin monooxygenase- 
generated N-hydroxypipecolic acid is a critical element of plant systemic immunity. Cell 173, 456-469.e416.

Hoth, S., Morgante, M., Sanchez, J. P., Hanafey, M. K., Tingey, S. V., Chua, N. H., 2002.

Genome-wide gene expression profiling in Arabidopsis thaliana reveals new targets of abscisic acid and largely impaired gene regulation in the abil-1 mutant. J. Cell Sci. 115, 4891-4900.

Jia, W., Wang, Y., Zhang, S., Zhang, J., 2002. Salt-stress-induced ABA accumulation is more sensitively triggered in roots than in shoots. J. Exp. Bot. 53, 2201-2206.

Joseph, M. P., Papdi, C., Kozma-Bognár, L., Nagy, I., López-Carbonell, M., Rigó, G., Koncz, C., Szabados, L., 2014. The Arabidopsis ZINC FINGER PROTEIN3 interferes with abscisic acid and light signaling in seed germination and plant development. Plant Physiol. 165, 12031220.

Jurkowski, G. I., Smith, R. K., Jr., Yu, I. C., Ham, J. H., Sharma, S. B., Klessig, D. F., Fengler, K. A., Bent, A. F., 2004. Arabidopsis DND2, a second cyclic nucleotide-gated ion channel gene for which mutation causes the "defense, no death" phenotype. Mol. Plant Microbe Interact. 17, 511-520.

Kaurilind, E., Xu, E., Brosché, M., 2015. A genetic framework for $\mathrm{H}_{2} \mathrm{O}_{2}$ induced cell death in Arabidopsis thaliana. BMC Genomics 16, 837.

Kazan, K., Manners, J. M., 2009. Linking development to defense: auxin in plant pathogen interactions. Trends Plant Sci. 14, 373-382.

Keisa, A., 2013. Regulation of hypersensitive response in barley (doctoral thesis). University of Latvia.

Keisa, A., Kanberga-Silina, K., Nakurte, I., Kunga, L., Rostoks, N., 2011. Differential disease resistance response in the barley necrotic mutant necl BMC Plant Biol. 11, 66. 
Keisa, A., Nakurte, I., Kunga, L., Kale, L., Rostoks, N., 2013. Increased auxin content and altered auxin response in barley necrotic mutant necl. In: Zhang, G., Li, C., Liu, X. (Eds.), Advance in Barley Sciences. Springer Netherlands, pp. 229-241.

Kepinski, S., Leyser, O., 2005. The Arabidopsis F-box protein TIR1 is an auxin receptor. Nature $435,446-451$.

477 Kollist, T., Moldau, H., Rasulov, B., Oja, V., Rämma, H., Hüve, K., Jaspers, P., Kangasjärvi, J., 478 Kollist, H., 2007. A novel device detects a rapid ozone-induced transient stomatal closure in 479 intact Arabidopsis and its absence in abi2 mutant. Physiol. Plantarum 129, 796-803.

480 Koornneef, M., Reuling, G., Karssen, C. M., 1984. The isolation and characterization of abscisic 481 acid-insensitive mutants of Arabidopsis thaliana. Physiol. Plantarum 61, 377-383.

482 Leng, Q., Mercier, R. W., Yao, W., Berkowitz, G. A., 1999. Cloning and first functional 483 characterization of a plant cyclic nucleotide-gated cation channel. Plant Physiol. 121, 753484761.

485 Leon-Kloosterziel, K. M., Gil, M. A., Ruijs, G. J., Jacobsen, S. E., Olszewski, N. E., Schwartz, 486 S. H., Zeevaart, J. A., Koornneef, M., 1996. Isolation and characterization of abscisic acid487 deficient Arabidopsis mutants at two new loci. Plant J. 10, 655-661.

488 Leung, J., Giraudat, J., 1998. Abscisic acid signal transduction. Annu. Rev. Plant Physiol. Plant 489 Mol. Biol. 49, 199-222.

490 Livak, K. J., Schmittgen, T. D., 2001. Analysis of relative gene expression data using real-time 491 quantitative PCR and the 2(-Delta Delta C(T)) method. Methods 25, 402-408.

492 Lorrain, S., Vailleau, F., Balague, C., Roby, D., 2003. Lesion mimic mutants: keys for 493 deciphering cell death and defense pathways in plants? Trends Plant Sci. 8, 263-271. 
Normanly, J., 2010. Approaching cellular and molecular resolution of auxin biosynthesis and metabolism. Cold Spring Harb. Perspect. Biol. 2, a001594.

Royer, D. L., 2001. Stomatal density and stomatal index as indicators of paleoatmospheric $\mathrm{CO}_{2}$ concentration. Review of Palaeobotany and Palynology 114, 1-28.

Rostoks, N., Schmierer, D., Mudie, S., Drader, T., Brueggeman, R., Caldwell, D. G., Waugh, R., Kleinhofs, A., 2006. Barley necrotic locus necl encodes the cyclic nucleotide-gated ion channel 4 homologous to the Arabidopsis HLM1 Mol. Genet. Genomics 275, 159-168.

Sakata, T., Oshino, T., Miura, S., Tomabechi, M., Tsunaga, Y., Higashitani, N., Miyazawa, Y., Takahashi, H., Watanabe, M., Higashitani, A., 2010. Auxins reverse plant male sterility caused by high temperatures. Proc. Natl. Acad. Sci. U. S. A. 107, 8569-8574.

Sauter, A., Davies, W. J., Hartung, W., 2001. The long-distance abscisic acid signal in the droughted plant: the fate of the hormone on its way from root to shoot. J. Exp. Bot. 52, 19911997.

Schneider, C. A., Rasband, W. S., Eliceiri, K. W., 2012. NIH Image to ImageJ: 25 years of image analysis. Nature Methods 9, 671-675.

Schroeder, J. I., Allen, G. J., Hugouvieux, V., Kwak, J. M., Waner, D., 2001. Guard cell signal transduction. Annu. Rev. Plant Physiol. Plant Mol. Biol. 52, 627-658.

Sherman, T., Fromm, H., 2009. Physiological roles of cyclic nucleotide gated channels in plants

Signaling in Plants. In: Mancuso, S., Baluška, F. (Eds.). Springer Berlin Heidelberg, pp. 91-106.

Shimazaki, K., Doi, M., Assmann, S. M., Kinoshita, T., 2007. Light regulation of stomatal movement. Annu. Rev. Plant Biol. 58, 219-247. 
Söderman, E. M., Brocard, I. M., Lynch, T. J., Finkelstein, R. R., 2000. Regulation and function of the Arabidopsis $A B A$-insensitive 4 gene in seed and abscisic acid response signaling networks. Plant Physiol. 124, 1752-1765.

Tan, X., Calderon-Villalobos, L. I., Sharon, M., Zheng, C., Robinson, C. V., Estelle, M., Zheng, N., 2007. Mechanism of auxin perception by the TIR1 ubiquitin ligase. Nature 446, 640-645.

Wang, Y.-F., Munemasa, S., Nishimura, N., Ren, H.-M., Robert, N., Han, M., Puzõrjova, I., Kollist, H., Lee, S., Mori, I., Schroeder, J. I., 2013. Identification of cyclic GMP-activated nonselective $\mathrm{Ca}^{2+}$-permeable cation channels and associated $C N G C 5$ and $C N G C 6$ genes in Arabidopsis guard cells. Plant Physiol. 163, 578-590.

Wang, L., Hua, D., He, J., Duan, Y., Chen, Z., Hong, X., Gong, Z., 2011. Auxin Response Factor2 (ARF2) and its regulated homeodomain gene $H B 33$ mediate abscisic acid response in Arabidopsis. PLoS Genet. 7, e1002172.

Wang, Y., Kang, Y., Ma, C., Miao, R., Wu, C., Long, Y., Ge, T., Wu, Z., Hou, X., Zhang, J., Qi, Z., 2017. CNGC2 is a Ca2+iInflux channel that prevents accumulation of apoplastic $\mathrm{Ca}^{2+}$ in the leaf. Plant Physiol. 173, 1342-1354.

Xu, J., Li, Y., Wang, Y., Liu, H., Lei, L., Yang, H., Liu, G., Ren, D., 2008. Activation of MAPK kinase 9 induces ethylene and camalexin biosynthesis and enhances sensitivity to salt stress in Arabidopsis. J. Biol. Chem. 283, 26996-27006.

Xu, W., Jia, L., Shi, W., Liang, J., Zhou, F., Li, Q., Zhang, J., 2013. Abscisic acid accumulation modulates auxin transport in the root tip to enhance proton secretion for maintaining root growth under moderate water stress. New Phytol. 197, 139-150.

Yu, H., Chen, X., Hong, Y.-Y., Wang, Y., Xu, P., Ke, S.-D., Liu, H.-Y., Zhu, J.-K., Oliver, D. J., Xiang, C.-B., 2008. Activated expression of an Arabidopsis HD-START protein confers 


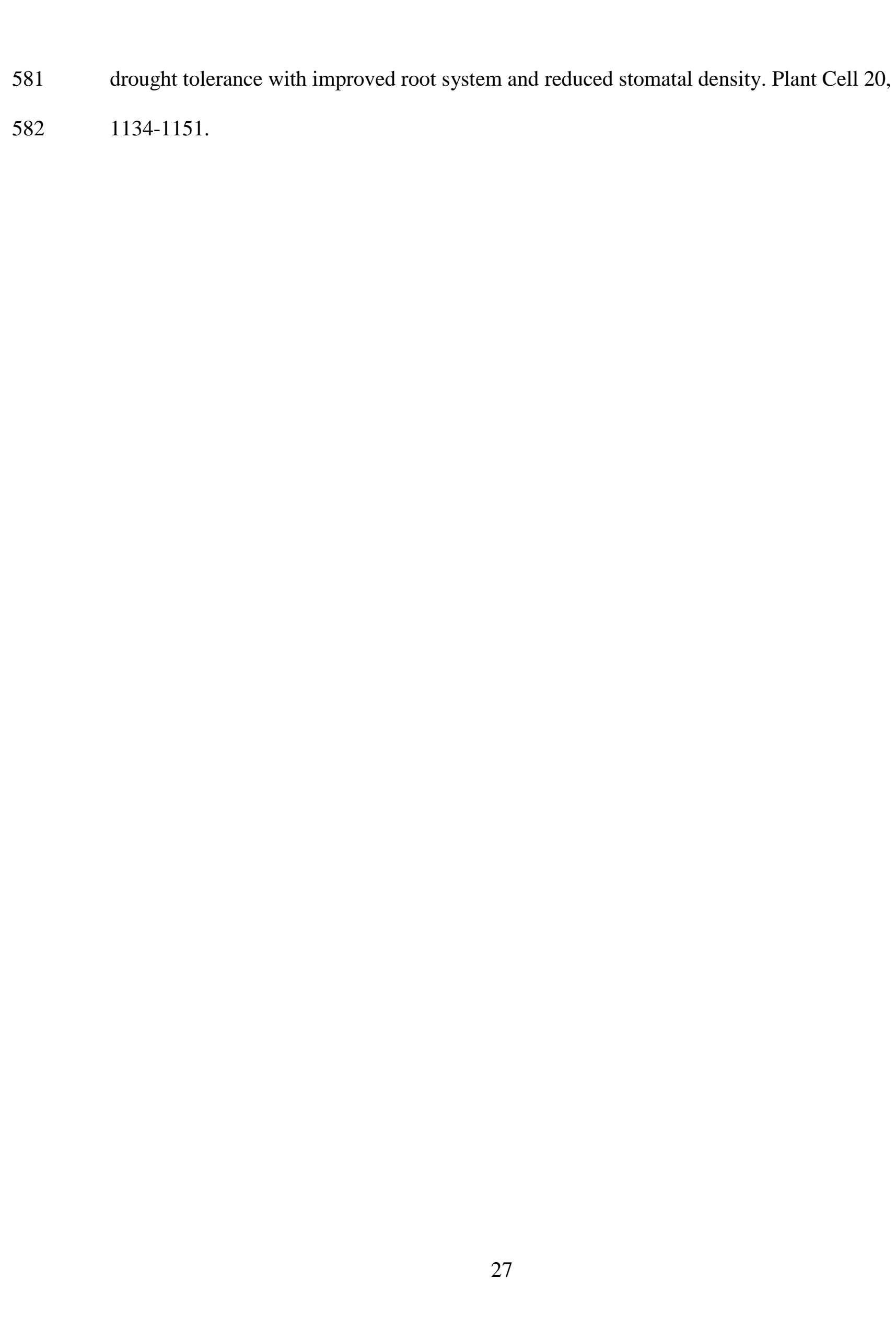


83 Table 1. Description of Arabidopsis mutants used in the study.

\begin{tabular}{|c|c|c|c|c|c|}
\hline & Genetic & & Gene & Relevant phenotype & Reference \\
\hline Mutant & background & Type of mutation & & & \\
\hline aba2-1 & Col-0 & $\begin{array}{l}\text { EMS, G to A substitution } \\
\text { at Ser262Asn }\end{array}$ & $A B A 2$ & ABA deficient 2 & $\begin{array}{l}\text { Leon- } \\
\text { Kloosterziel et } \\
\text { al., } 1996\end{array}$ \\
\hline abil-1 & Col- $0^{\mathrm{a}}$ & $\begin{array}{l}\text { EMS, substitution at } \\
\text { Gly180Asp }\end{array}$ & $A B I I$ & ABA insensitive 1 & $\begin{array}{l}\text { Koornneef et } \\
\text { al., } 1984\end{array}$ \\
\hline$d n d 2-1$ & Col-0 & $\begin{array}{l}\text { Ethylmethane-sulfonate } \\
\text { (EMS), G to A } \\
\text { substitution at Trp } 89 \text {, } \\
\text { premature stop codon }\end{array}$ & $\begin{array}{l}\text { DND2 or } \\
\text { HLM1 or } \\
\text { AtCGNC4 }\end{array}$ & Defense no death & $\begin{array}{l}\text { Jurkowski et } \\
\text { al., } 2004\end{array}$ \\
\hline fmol & Col-0 & $\begin{array}{l}\text { T-DNA insertion line } \\
\text { SALK_026163 }\end{array}$ & FMOI & $\begin{array}{l}\text { Deficient in systemic } \\
\text { acquired resistance } \\
\text { (SAR) }\end{array}$ & $\begin{array}{l}\text { Mishina and } \\
\text { Zeier, } 2006\end{array}$ \\
\hline $\operatorname{sid} 2-1$ & Col-0 & $\begin{array}{l}\text { EMS, } C \text { to T substitution } \\
\text { in exon } 9 \text { at Glu449, } \\
\text { premature stop codon }\end{array}$ & SID2 & $\begin{array}{l}\text { Deficient in } \\
\text { isochorismate synthase } \\
\text { (salicylic acid (SA) } \\
\text { biosynthesis) }\end{array}$ & $\begin{array}{l}\text { Nawrath and } \\
\text { Métraux, } 1999\end{array}$ \\
\hline
\end{tabular}

${ }^{a}$ The original abil-1 mutant (Koornneef et al., 1984) was in Ler background, while in this study an equivalent mutant in Col-0 background was used. 


\begin{tabular}{llll}
\hline \multicolumn{2}{l}{ Primer sequences for quantitative real-time PCR analysis of gene expression } & \\
\hline ABI1 & F: CGGCAAAACTGCACTTCCAT & RT qPCR & Anderson et al., 2004 \\
ABI4 & R: CACGAGCTCCATTCCACTGAA & & Joseph et al., 2014 \\
& R: AGGCCAAATGGTCGAAGATCCATC & & \\
AMI1 & F: CGCCTCCTTCTCTACAGGGTCTTAC & RT qPCR & This study \\
AtACTIN2 & F: GATTCAGATGCCCAGAAGTCTTGT & RT qPCR & Alcázar et al., 2009 \\
& R: TGGATTCCAGCAGCTTCCAT & & This study \\
CSN5 & F: CTGAGACAAGGGTTAATGCTCAGG & RT qPCR & \\
& R: AGGGTGAGAGTGATACCATCCAAC & & Sakata et al., 2010
\end{tabular}




$\begin{array}{llll}\text { TIR1 } & \text { F: GCCCTAAACTGCAGCGCC } & \text { RT qPCR } & \text { Sakata et al., } 2010 \\ \text { YUC1 } & \text { R: CCCCTGTTCCGTCAATGCC } & \\ & \text { F: ATTCCGGCATGGAAATTAGCTTAG } & \text { RT qPCR } & \text { This study } \\ \text { RUC2 } & \text { F: GGGATGGAAGTTTGTTTAGACCTTTGC } & \text { RT qPCR } & \text { Sakata et al., } 2010 \\ & \text { R: CTGGAAACCACTTGAGCAGGC } & & \\ \text { FUC6 } & \text { F: GGATCTCTGCAACTTCGGTGC } & \text { RT qPCR } & \text { Sakata et al., } 2010 \\ & \text { R: GAACATGGACAGCCCAAAAGTTGAAG } & & \end{array}$


LK - performed the experiments and drafted the manuscript

IN - performed HPLC analysis and drafted the appropriate section of the manuscript

PJ - measured stomatal conductance and drafted the appropriate section of the manuscript

LKJ - performed the experiments

$M B$ - designed the study, performed the experiments and drafted the manuscript

$\mathrm{NR}$ - designed the study and wrote the manuscript

All authors have reviewed the final version of the manuscript submitted for publication. 
A

B
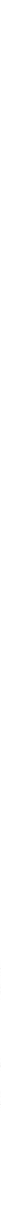

口Col-0 口dnd2

口Col-0 adnd2 


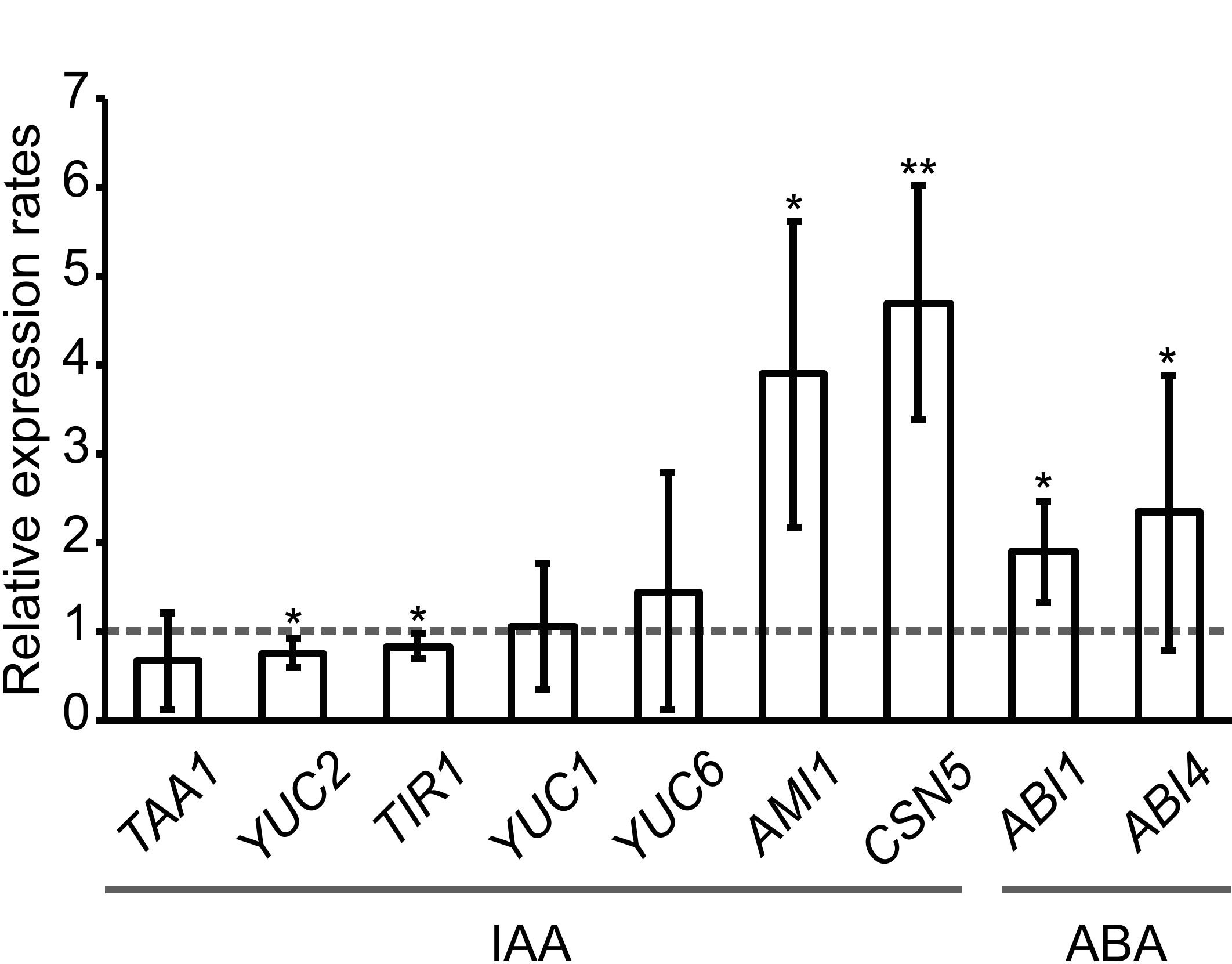

Figure

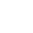
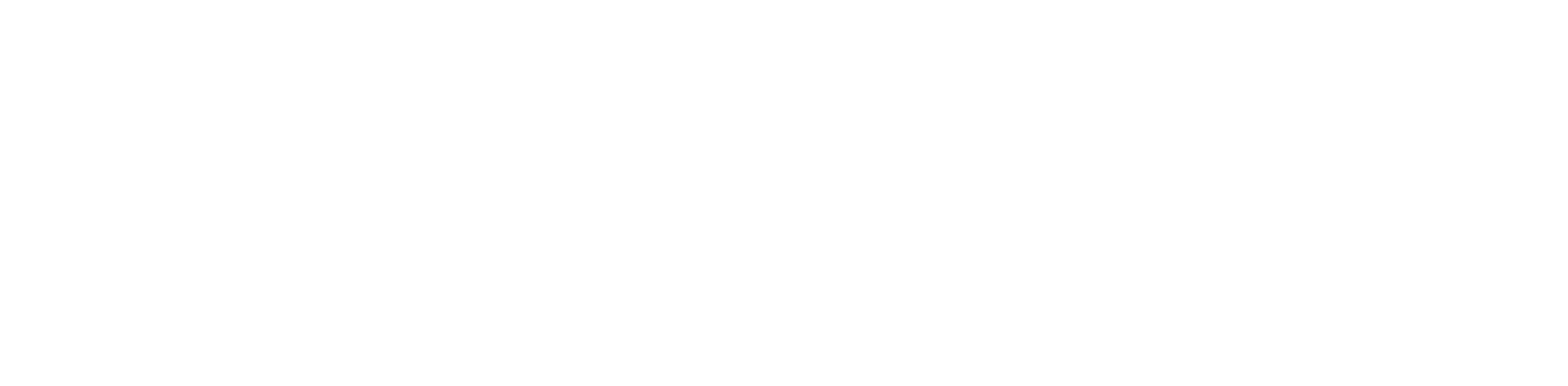

(2)

$(2$

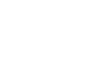

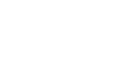

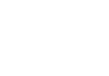

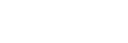
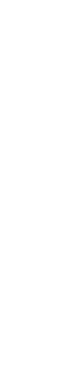
A

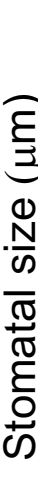

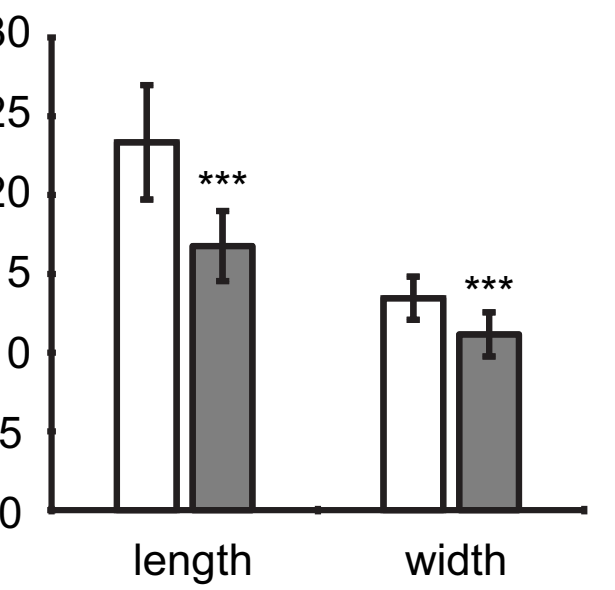

B

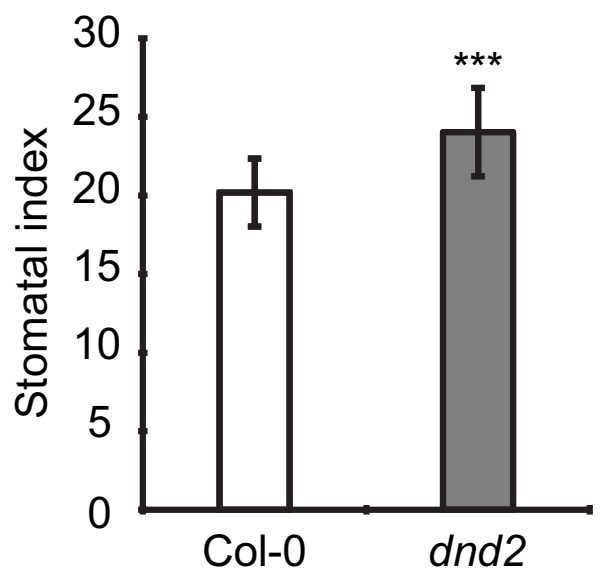

C

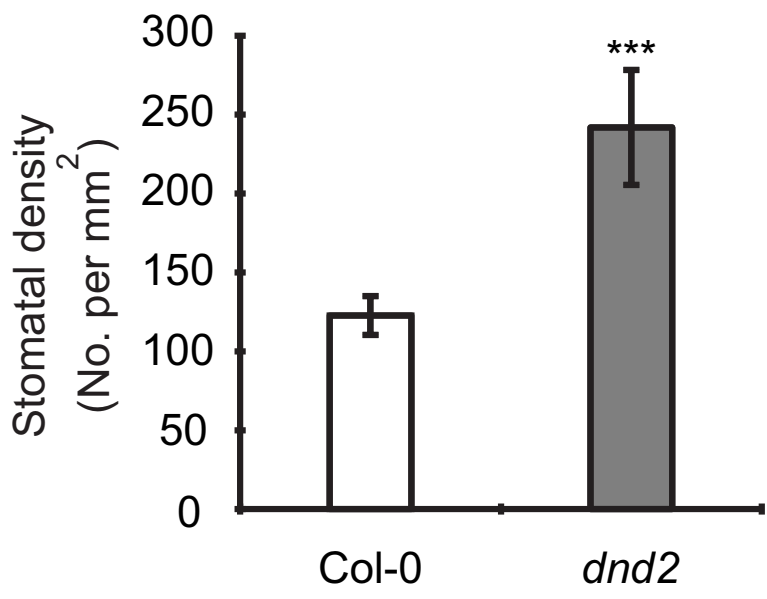


(6)

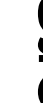

\&

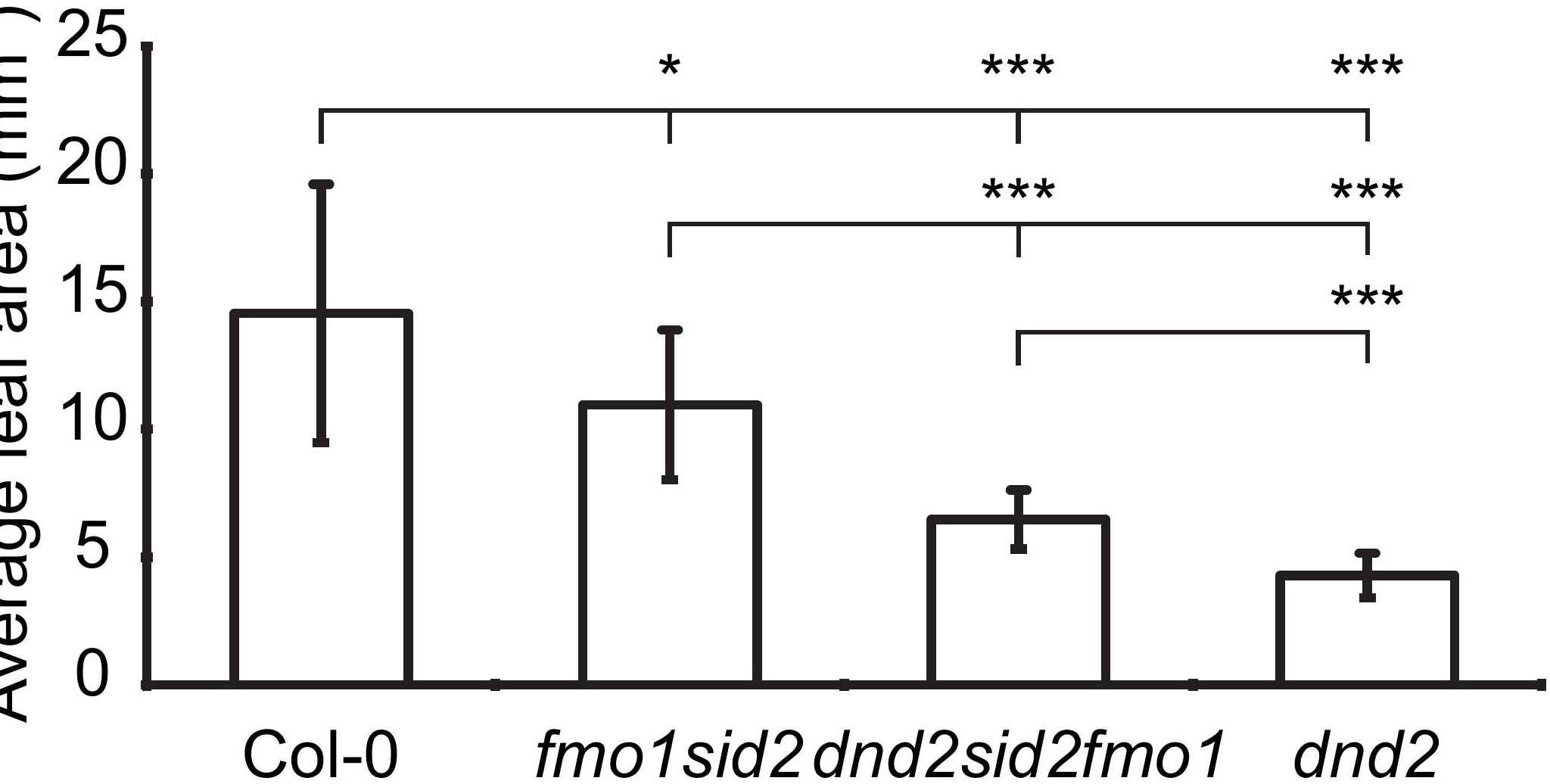

\section{Col-0 fmo1sid2dnd2sid2fmo1 dnd2

.


Supplementary figure
Click here to download Supplementary material: Kale_Supplemental_figure1.pdf

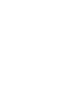

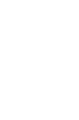

$\sqrt{2}$

(1)

(1)

$\sqrt{2}$ (a) 

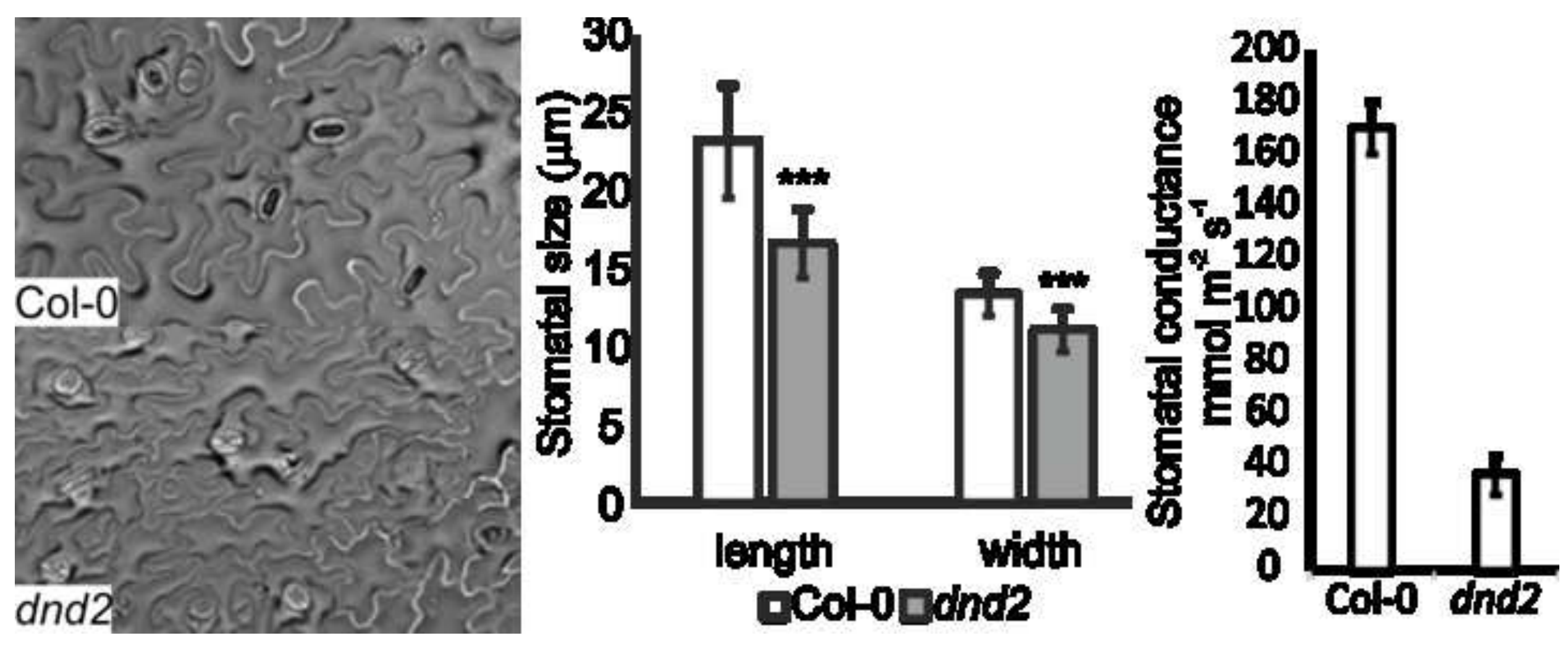
- Arabidopsis dnd2 mutant shows increased IAA and ABA content

- Hormonal changes in $d n d 2$ are linked to reduced stomatal size and conductance

- Arabidopsis $d n d 2$ is useful to study cross-talk between abiotic and biotic stress 